\title{
Electrocardiography in Athletes - How to Identify High-risk Subjects
}

\author{
Belinda Gray, ${ }^{1,2,3}$ Aneil Malhotra ${ }^{1,4}$ and Sanjay Sharma ${ }^{1,5}$ \\ 1. Cardiology Clinical Academic Group, St George's University of London, London, UK; 2. Faculty of Medicine and Health, University of \\ Sydney, Sydney, Australia; 3. Department of Cardiology, Royal Prince Alfred Hospital, Camperdown, New South Wales, Australia; 4. Division of \\ Cardiovascular Sciences, University of Manchester, Manchester, UK; 5. St George's University Hospitals NHS Foundation Trust, London, UK
}

A thletes are the fittest individuals in our society; however, they paradoxically carry a higher risk of sudden death compared with sedentary individuals. A number of underlying structural, arrhythmic and inherited cardiac conditions may increase the athlete's risk of sudden cardiac death in sports. Many of the affected athletes can be diagnosed on pre-participation screening with history, physical examination and a 12-lead electrocardiogram (ECG). However, physiological adaptation to exercise also leads to structural and functional changes within the heart which have an impact on the ECG and may be misinterpreted as pathology. It is imperative that any physician involved in the assessment of elite athletes is trained in the accurate interpretation of the athlete's ECG to ensure potentially dangerous pathology is detected, but also to ensure that the athlete is not inappropriately excluded from competition or subjected to inappropriate further investigations that are both stressful for the athlete and their family, and costly for the health system. This review article highlights what is expected in normal athletic ECG adaptation and then highlight important 'red flags' of potential underlying pathology in elite athletes.

\section{Keywords}

Athlete, screening, electrocardiogram, sudden cardiac death, channelopathy, cardiomyopathy

Disclosures: Belinda Gray, Aneil Malhotra and Sanjay Sharma have no financial or non-financial relationships or activities to declare in relation to this article.

Review Process: Double-blind peer review.

Compliance with Ethics: This article involves a review of the literature and did not involve any studies with human or animal subjects performed by any of the authors. No information has been included that could reveal athlete identity where representative electrocardiograms have been included.

Authorship: The named authors meet the International Committee of Medical Journal Editors (ICMJE) criteria for authorship of this manuscript, take responsibility for the integrity of the work as a whole, and have given final approval for the version to be published. Access: This article is freely accessible at touchCARDIOLOGY.com @) Touch Medical Media 2020. Received: 12 January 2020

Accepted: 5 March 2020

Published Online: 20 April 2020

Citation: European Journal of Arrhythmia

\& Electrophysiology. 2020;6(1):24-31

Corresponding Author: Sanjay Sharma,

St George's University of London, Cranmer Terrace, London SW17 ORE, UK. E: sasharma@sgul.ac.uk

Support: No funding was received in the publication of this article.
Athletes represent the fittest individuals in our society, yet paradoxically carry an increased risk of sudden cardiac death (SCD) when compared to sedentary individuals with the same cardiac disease. ${ }^{1,2}$ Two recent studies have provided a realistic prevalence of young SCD in both the general population and in elite athletes. A population-based study from Australia and New Zealand showed the incidence of young SCD in the general population to be 1.3/100,000 among individuals aged 1-35 years, whilst a recent study of cardiac screening in young adolescent football players in the UK showed a much higher incidence of SCD of 6.8/100,000 in this athletic population. ${ }^{3,4}$ Indeed, SCD is the most common non-traumatic cause of mortality in athletes. ${ }^{5}$ Studies have shown that sports activity in adolescents can trigger an increased rate of sudden death, especially in the presence of underlying structural heart disease. ${ }^{2}$ Up to $66 \%$ of SCD cases in athletes have been shown to be potentially identifiable on pre-participation electrocardiogram (ECG), including inherited, electrical or structural abnormalities. ${ }^{5-7}$ In addition, there are a number of physiological adaptations to the ECG in high-level athletes, which can be misinterpreted as pathology and lead to a number of expensive and unnecessary further investigations in the athlete with a risk of increased stress, anxiety and cost to the health system. ${ }^{8}$

Whether the ECG is performed for screening or for diagnosis, the ability of the reviewing physician to identify normal athletic adaptation is critical. In the last 10 years, a number of studies have highlighted some key electrical features of normal physiological adaptation in a number of different ethnic groups and have led to multiple revisions of the original 2010 recommendations for ECG interpretation in athletes. ${ }^{9-15}$ This has led to the recently updated 'International recommendations for ECG interpretation in athletes', published in 2017. ${ }^{5}$ These recommendations are more specific for identifying athletes with disease, and resulted in a reduction in the number of athletes with an abnormal ECG - from 22\% to 3\% compared with the 2010 European Society of Cardiology (ESC) criteria. ${ }^{16}$ Currently, the ESC, as well as a number of leading sporting organisations including the International Olympic Committee, recommend screening of elite athletes for underlying cardiovascular disease using a combination of history, examination and pre-participation ECG. ${ }^{17}$ Therefore, it is essential that the reviewing clinician has expertise in identifying athletes with high-risk ECG markers and differentiating normal athletic adaptation from pathology.

\section{Normal athletic adaptation of the electrocardiogram}

There are a number of physiological adaptations that occur in the heart as a consequence of exercising intensively for $>4$ hours/week, including increased vagal tone and chamber dilatation. These adaptations lead to specific associated changes on the ECG that can be considered normal and do not warrant further investigations (Table 1). ${ }^{5}$ Sinus bradycardia is observed in the majority of athletes; however, a heart rate $<35 \mathrm{bpm}$ is rare, except in endurance athletes. ${ }^{18}$ 
Table 1: Electrocardiogram changes in athletes

\begin{tabular}{|c|c|c|}
\hline $\begin{array}{l}\text { Normal ECG Findings } \\
\text { (no further evaluation } \\
\text { required) }\end{array}$ & $\begin{array}{l}\text { Borderline ECG } \\
\text { findings } \\
\text { (further evaluation } \\
\text { if } \geq 2 \text { findings) }\end{array}$ & $\begin{array}{l}\text { Abnormal ECG findings } \\
\text { (require further evaluation) }\end{array}$ \\
\hline $\begin{array}{l}\text { - Voltage criteria for } \\
\text { - IVH/RVH } \\
\text { - Incomplete RBBB } \\
\text { - Early repolarisation } \\
\text { - ST elevation with } \\
\text { TWI V1-V4 (black } \\
\text { athlete) } \\
\text { - } \text { Sinus bradycardia/ } \\
\text { arrhythmia } \\
\text { - Ectopic atrial/ } \\
\text { junctional rhythm } \\
\text { - First-degree AV } \\
\text { block } \\
\text { - Mobitz type } 1 \\
\text { second-degree AV } \\
\text { block } \\
\text { - TWI V1-V3 age } \\
<16 \text { years (juvenile } \\
\text { pattern) }\end{array}$ & $\begin{array}{l}\text { - } \text { Left axis deviation } \\
\text { - } \text { Right axis } \\
\text { deviation } \\
\text { - Left atrial } \\
\text { enlargement } \\
\text { - } \text { Right atrial } \\
\text { - enlargement } \\
\text { - Complete RBBB }\end{array}$ & $\begin{array}{l}\text { - } \text { T-wave inversion } \\
\text { - } \text { ST-segment depression } \\
\text { - } \text { Pathologic Q waves } \\
\text { - } \text { Complete LBBB } \\
\text { - } \text { QRS } \geq 140 \text { ms duration } \\
\text { - } \text { Epsilon wave } \\
\text { - } \text { Ventricular pre-excitation } \\
\text { - Prolonged QT interval } \\
\text { - } \text { Brugada type } 1 \text { pattern } \\
\text { - Profound sinus bradycardia } \\
<30 \text { bpm } \\
\text { - } \text { Severe first-degree AV } \\
\text { block ( } \geq 400 \text { ms) } \\
\text { - } \text { Third-degree AV block } \\
\text { - } \geq 2 \text { PVCs } \\
\text { - Atrial tachyarrhythmias } \\
\text { - } \text { Ventricular arrhythmias }\end{array}$ \\
\hline
\end{tabular}

Data taken from Sharma, et al., 2017. ${ }^{5}$

$A V=$ atrioventricular; $E C G$ = electrocardiogram; $L B B B=$ left bundle branch block; $\angle V H=$ left ventricular hypertrophy; $P V C=$ premature ventricular contractions;

$R B B B=$ right bundle branch block; $R V H=$ right ventricular hypertrophy;

$T W I=T$-wave inversion.

Sinus arrhythmia is also common, occurring in up to $70 \%$ of athletes, whilst first-degree atrioventricular (AV) block is present in approximately 10-15\%. ${ }^{12,13,19}$ The PR interval in an athletic individual is not considered to be pathologically abnormal until it is $>400$ ms. ${ }^{5}$ Junctional rhythm, Mobitz type 1 second-degree AV block (Wenkebach) and sinus pauses (up to 2 seconds) are seen in a proportion of athletes, especially during sleep..$^{20}$ Other changes attributable to high vagal tone include ectopic atrial rhythm and wandering atrial pacemaker. ${ }^{21}$ Higher degree of AV block, including prolonged sinus pauses $>3$ seconds during waking hours, Mobitz type 2 second-degree AV block and third-degree AV block, are exceptionally rare in athletes and warrant further investigation. ${ }^{5}$

Repolarisation changes are also commonly seen on the athlete's ECG. Early repolarisation patterns with J-point elevation, saddle-backed ST-segment elevation, notching of the J point and slurring of the downstroke of the S-wave, are common in athletes and present in up to $25 \%$ white athletes and up to $40 \%$ of black athletes. ${ }^{13}$

Despite some evidence of increased early repolarisation in survivors of cardiac arrest with idiopathic ventricular fibrillation, ${ }^{22}$ there are currently no data to support increased risk of SCD in athletes with early repolarisation in isolation, and therefore should be considered benign in the absence of other clinical markers of pathology. ${ }^{5,21}$ There are also well-described repolarisation abnormalities that have been observed in up to $13 \%$ of black athletes with a pattern of convex (upsloping) ST elevation followed by T-wave inversion $\mathrm{V} 1-\mathrm{V} 4$, which is considered normal variation in black athletes. ${ }^{5,13}$

Voltage criteria for left and right ventricular hypertrophy in the absence of other abnormalities (such as T-wave inversion) are common in athletes
Table 2: Electrocardiographic red flags of underlying structural heart disease

\begin{tabular}{|l|l|}
\hline ECG feature & Potential underlying diagnoses \\
\hline Inferolateral T-wave inversion & HCM* \\
& DCM \\
& Myocarditis \\
& Coronary artery disease \\
& LVNC \\
\hline Anterior T-wave inversion & ARVC \\
\hline Complete LBBB & Myocarditis \\
& DCM \\
\hline QT prolongation & Sarcoidosis \\
& HCM \\
\hline Pathologic Q waves & LVNC \\
\hline Brugada type 1 pattern & LQTS \\
\hline Multiple PVCs & HCM \\
& ISChaemic heart disease/myocardial \\
infarction
\end{tabular}

* T-wave inversion can be widespread in apical HCM.

$A R V C=$ arrhythmogenic right ventricular cardiomyopathy; $D C M=$ dilated cardiomyopathy; $E C G$ = electrocardiogram; $H C M$ = hypertrophic cardiomyopathy; $\angle B B B=$ left bundle branch block; $L Q T S=$ long QT syndrome; $L V N C=$ left ventricular noncompaction; $P V C=$ premature ventricular contractions; WPW $=$ Wolff-Parkinson-White.

and do not warrant further investigation. Large voltages are partly due to physiological increases in ventricular cavity size and mass, but are also commonly due to less distance between the heart and the ECG electrode in slim males. Voltage criteria for left and right ventricular hypertrophy are observed in $50-60 \%$ and $13 \%$ of male athletes, respectively.5.23

Right ventricular dilatation is a common manifestation of physiological adaptation to exercise..$^{24,25}$ This is believed to cause increased conduction time through the His-Purkinje fibres and manifests as incomplete right bundle branch block (RBBB) on ECG, which is seen in up to $30 \%$ of athletes. This ECG, showing QRS $<120$ ms and $r S R^{\prime}$ in V1, is considered a normal ECG pattern in athletes and does not warrant further investigation in an asymptomatic athlete. 12,15,19 Some athletes may demonstrate incomplete RBBB with J-point elevation and mildly ascending ST segments in the right praecordial leads (type 2 Brugada pattern). ${ }^{21}$ Repeating the ECG with the leads V1 and V2 placed higher in the second or third to exclude a spontaneous type 1 Brugada pattern (which is not a normal variant), is recommended. ${ }^{26}$

\section{Normal T-wave inversion patterns}

T-wave inversion in the general population and in white athletes is considered normal in V1-V2 and in leads III or aVF. In white athletes, anterior T-wave inversion beyond lead V2 is rare, particularly in men. ${ }^{27,28}$ In the black athletic population, anterior T-wave inversion is acceptable in V1-V4, especially when preceded by J-point elevation and upsloping ST segment which has been shown to be present in almost $13 \%$ of the black athlete popuation. ${ }^{13}$ Anterior T-wave 
Figure 1: Electrocardiogram of $(\mathrm{A})$ a 35-year-old white tennis player showing abnormal T-wave inversion in V1-V4 consistent with subsequent diagnosis of arrhythmogenic right ventricular cardiomyopathy, and (B) a 20-year-old black runner with lateral T-wave inversion and a diagnosis of apical hypertrophic cardiomyopathy
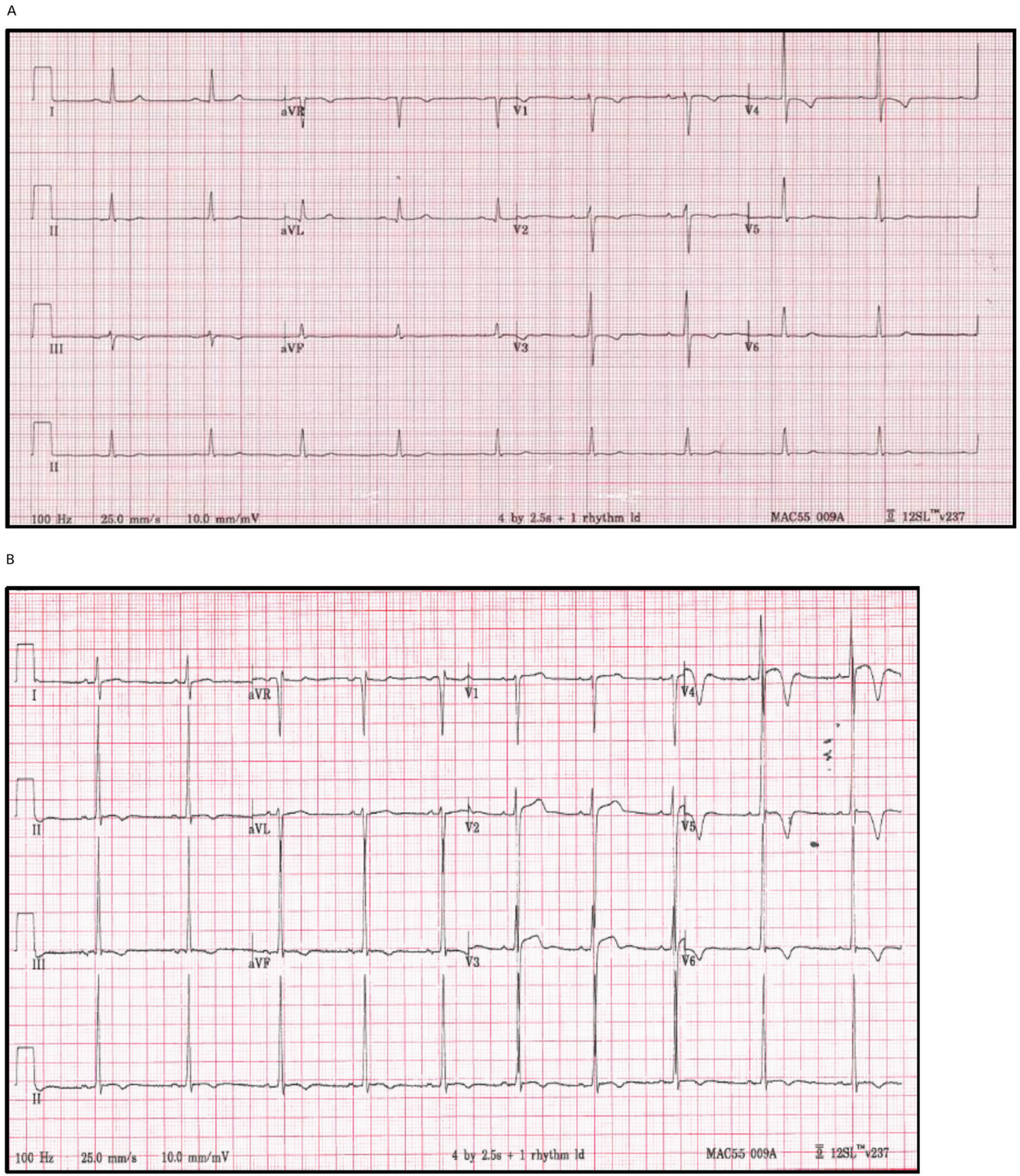

inversion is also more prevalent in endurance athletes compared with non-endurance athletes. T-wave inversion in leads V1-V2 is identified in $10 \%$ of endurance athletes and may extend to V3 in approximately $4 \% .{ }^{29}$ In young individuals, anterior T-wave inversion to lead V3 is known as the 'juvenile pattern' and is present in up to 3\% of young athletes and non-athletes aged <14 years old. However, this pattern rarely persists after age 16 in adolescent athletes. ${ }^{12,30}$

\section{Normal QT interval in athletes}

The normal QT interval in the general population is $<440 \mathrm{~ms}$ in men and $<460$ ms in women; however, athletes may exhibit a longer QT interval due to the effect of increased vagal tone or delayed repolarisation secondary to increased left ventricular mass. ${ }^{31}$ It is important to accurately measure the QT interval and exclude U waves, especially in leads V2-V4. The QT interval is best measured in leads II and V5. The QT should be corrected 
Figure 2: Electrocardiogram demonstrating Wolff-Parkinson-White syndrome with delta waves (pre-excitation), PR shortening and prolonged QRS duration

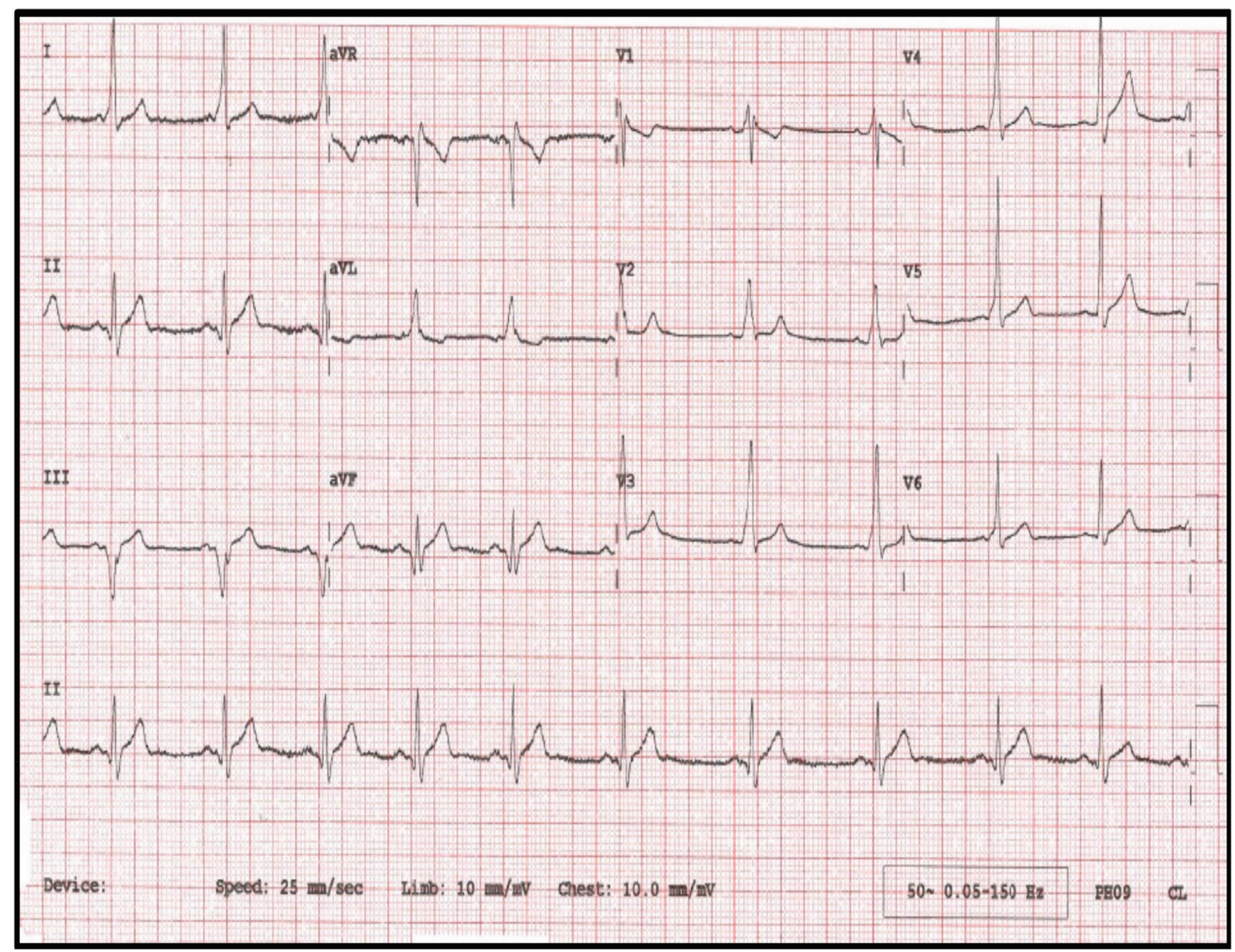

for heart rate using Bazett's formula (QTC $=\mathrm{QT} / \sqrt{\mathrm{RR}})$, accepting that it is less accurate at the extremes of heart rate (Bazett's formula tends to under-correct at high heart rates $>120 \mathrm{bpm}$ and over-correct at low heart rates $<40 \mathrm{bpm}){ }^{21}$ In cases of sinus arrhythmia it is best to use the averages of the QT and the RR interval, as this approach has been shown to have very high accuracy. ${ }^{32}$ The acceptable upper limits for a normal QT interval are $\leq 470 \mathrm{~ms}$ in males and $\leq 480 \mathrm{~ms}$ in females. With regards to the shortest QTC duration in athletes, a cut-off of $>320$ ms is accepted as the lower range of normal as $99.9 \%$ of athletes have a QTc in this range. ${ }^{33}$

\section{Abnormal electrocardiogram in athletes}

Underlying structural and electrical disease in athletes can lead to ECG changes that are beyond what would be acceptable for their degree of athletic activity. These changes should act as 'red flags' for the reviewing physician and initiate consideration of further cardiac investigations including echocardiography, Holter monitor testing, exercise tolerance testing and cardiac magnetic resonance (CMR) imaging (Table 2).

\section{Abnormal T-wave inversion}

T-wave inversion is a well-recognised manifestation in individuals with cardiomyopathies. Although some patterns of T-wave inversion are acceptable in young adolescents and in all black athletes, the presence of this anomaly should trigger a search for other clues in the history or the ECG to determine an underlying abnormality. ${ }^{13,34,35}$ Anterior T-wave inversion beyond $\mathrm{V} 2$ in adult non-black athletes is considered abnormal and should warrant further investigation to exclude arrhythmogenic (right ventricular) cardiomyopathy (ARVC). ${ }^{5}$ Other co-existing electrical anomalies that may favour the diagnosis include the presence of an epsilon wave (a distinct low amplitude signal between the end of the QRS complex and the onset of T-wave in leads V1-V3), delayed upstroke to the S-wave in V2, small limb lead complexes (QRS $<0.5 \mathrm{mV}$ ) and ventricular premature beats. 5,36 T-wave inversion in the lateral leads should raise the possibility of an underlying cardiomyopathy and warrant further investigation with echocardiogram \pm CMR imaging with late gadolinium enhancement to assess for myocardial fibrosis (Figure $1 A$ and $B$ ). Although T-wave inversion in the lateral leads has been documented in $4 \%$ of black male athletes and is unlikely to represent heart disease in all individuals, there are documented cases of black athletes with the abnormality that have either been diagnosed with cardiomyopathy or had an aborted sudden cardiac arrest. ${ }^{37}$ Therefore, all athletes with lateral T-wave inversion require further assessment irrespective of ethnicity.

The significance of inferior T-wave inversion is uncertain. This repolarisation anomaly is detected in $<0.3 \%$ of white athletes but present in $6 \%$ of black athletes. We have yet to diagnose a cardiomyopathy 
Figure 3: Electrocardiogram of a 25-year-old rower showing prolongation of the QT interval (QTC $=510 \mathrm{~ms})$

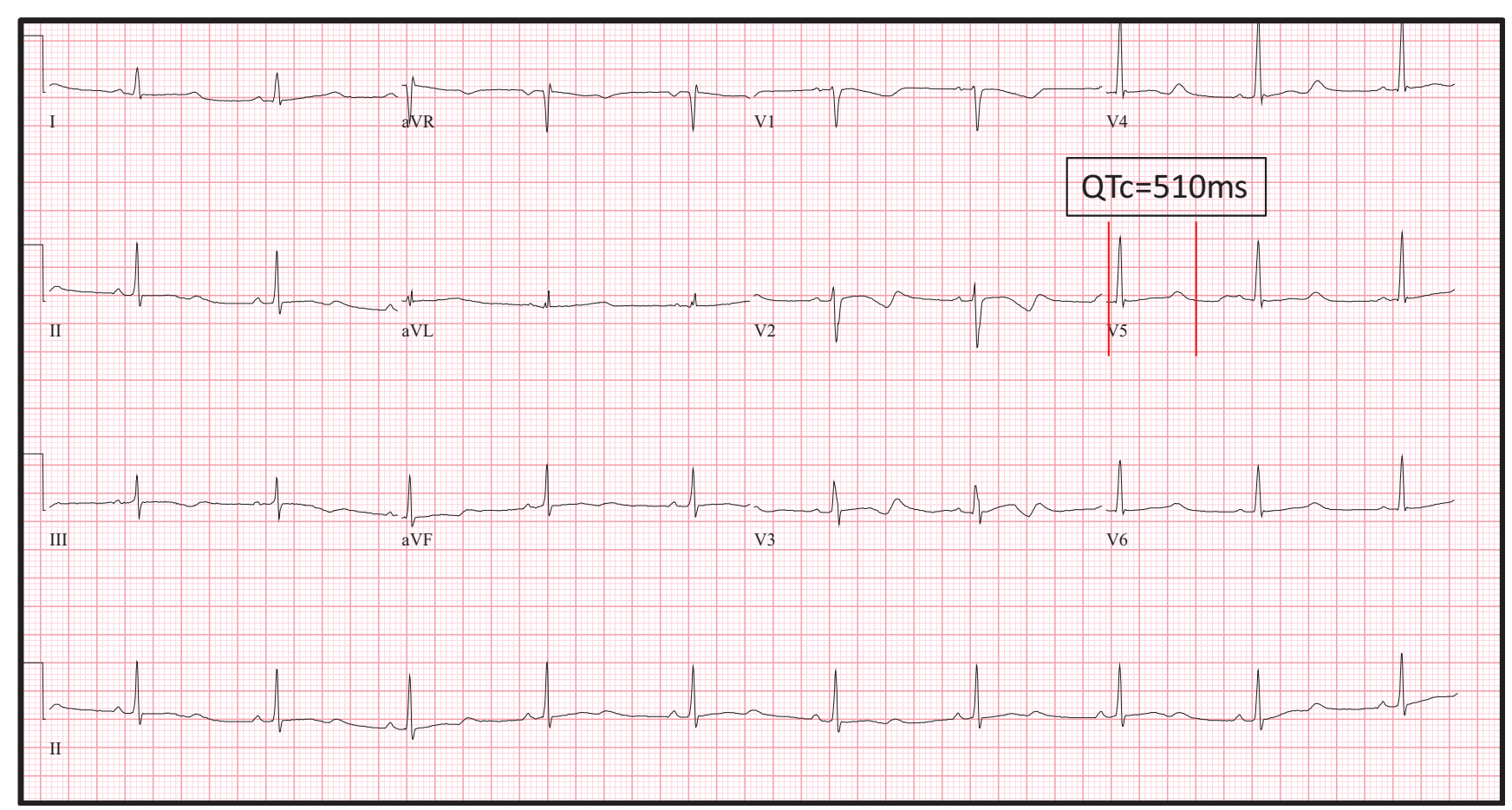

The athlete was subsequently found to carry a pathogenic KCNH2 variant (LOng QT syndrome 2).

Figure 4: Electrocardiogram demonstrating coved-type ST elevation in right praecordial leads consistent with a type 1 Brugada pattern

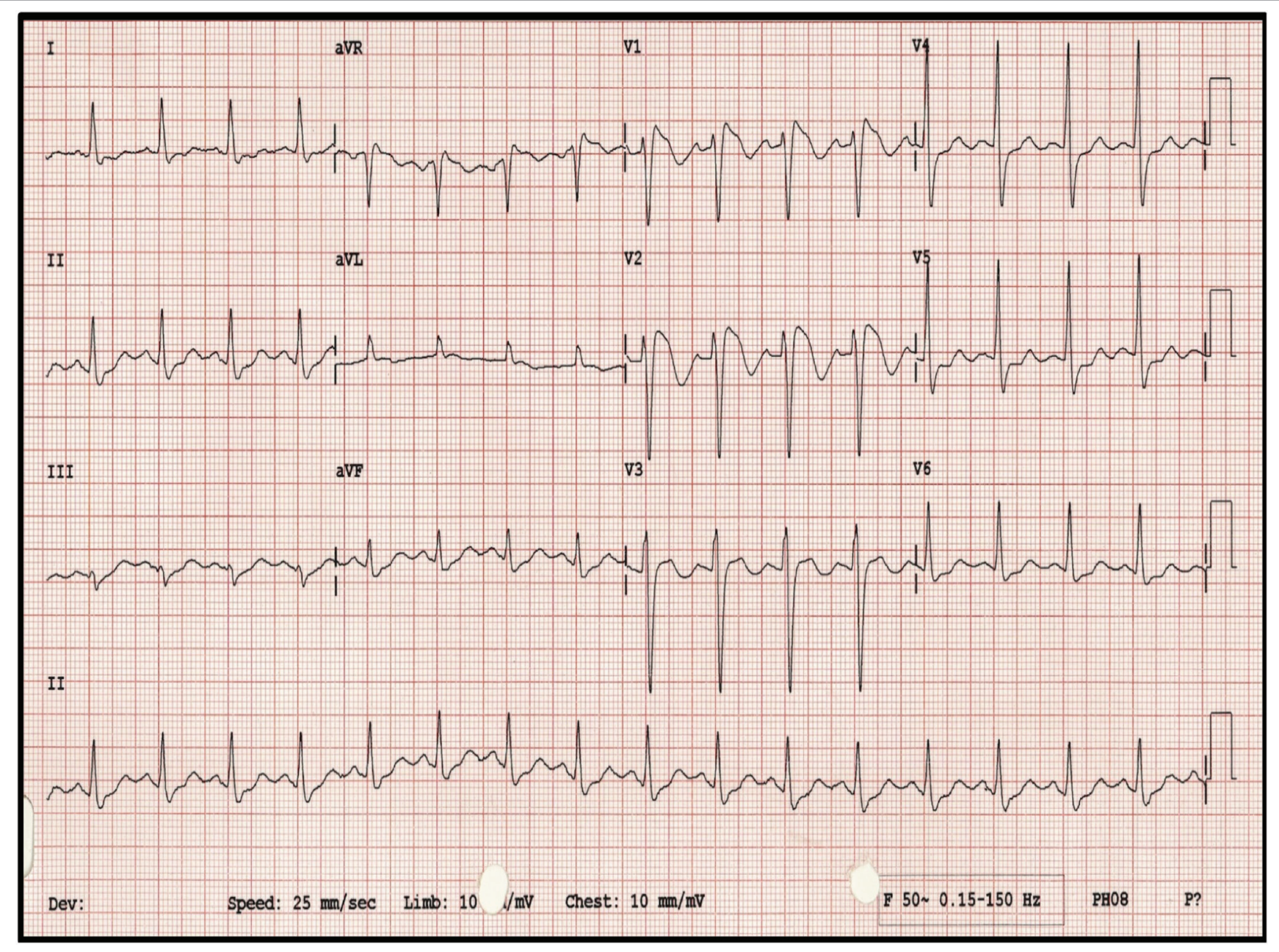




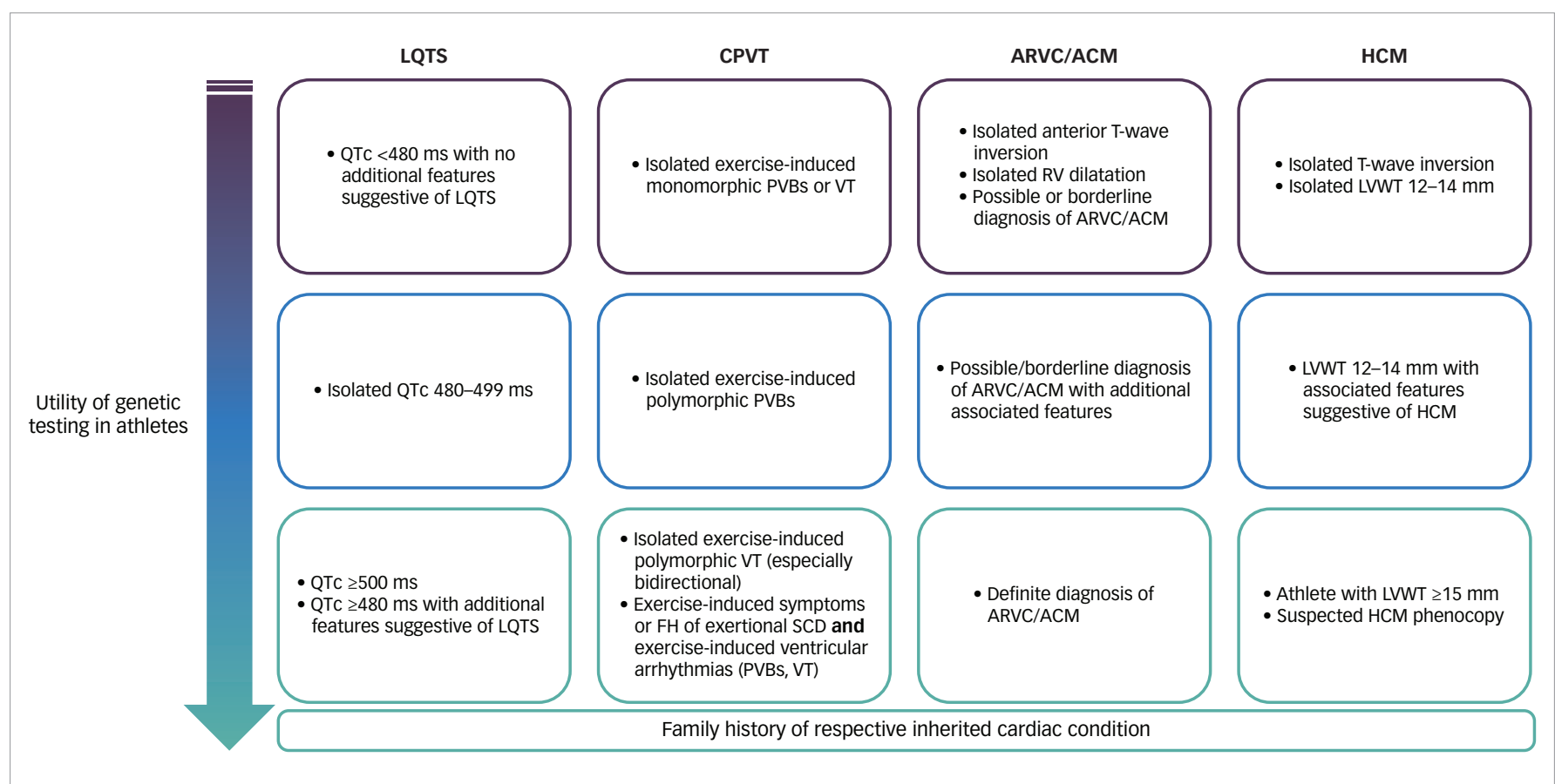

ACM = arrhythmogenic cardiomyopathy; $A R V C=$ arrhythmogenic right ventricular cardiomyopathy; CPVT = catecholaminergic polymorphic ventricular tachycardia;

$F H=$ family history; $H C M=$ hypertrophic cardiomyopathy; LQTS = Iong QT syndrome; LVWT = left ventricular wall thickness; $P V B=$ premature ventricular beat; $R V=$ right ventricle; $S C D=$ sudden cardiac death; $V T=$ ventricular tachycardia.

Modified from Gray and Semsarian, 2020. ${ }^{48}$

in a black athlete with isolated T-wave inversion; therefore, whilst it may be worthwhile to perform comprehensive investigations in white athletes with this abnormality, we would not consider any further investigations beyond echocardiogram in asymptomatic black athletes with isolated inferior T-wave inversion.

\section{ST-segment depression}

ST depression $\geq 0.5 \mathrm{~mm}(0.05 \mathrm{mV})$ in $\geq 2$ leads is abnormal; it is not a usual manifestation of athletic adaptation but is common in patients with cardiomyopathy and therefore should be investigated with an echocardiogram and consideration for CMR imaging in some cases. ${ }^{5}$

\section{Pathological Q-waves}

The criteria for pathological Q-waves in athletes has been updated in the international recommendations and is now defined as a $Q / R$ ratio of $\geq 0.25$ or $\geq 40 \mathrm{~ms}$ in duration in two or more leads. Pathological Q-waves may indicate underlying cardiomyopathy, infiltrative disease, accessory pathways or myocardial infarction. ${ }^{5}$ Occasionally V1-V2 may manifest pathological Q-waves as a pseudo-septal infarct pattern if the leads are placed too high relative to the cardiac position. ${ }^{34}$ Q-waves in isolation, particularly in lead $\mathrm{aVL}$, are relatively common in young athletes and should not be considered pathological unless they extend beyond the parameters described above. ${ }^{21}$

\section{Conduction delay patterns}

High vagal tone and tendency to bradycardia is a known manifestation of athletic adaptation and may be normal in some athletes; however, in athletes with profound first-degree AV block (PR $\geq 400 \mathrm{~ms}$ ) and profound sinus bradycardia (heart rate $<30$ bpm or sinus pause $>3$ secs), further investigation to exclude chronotropic incompetence (such as exercising on the spot) is indicated. High-grade AV block (Mobitz type 2 second-degree AV block or complete heart block) are abnormal and require further investigation with echocardiogram, Holter monitor, exercise tolerance testing and referral to an electrophysiologist. ${ }^{5}$ complete left bundle branch block (LBBB) pattern is rare in athletes and common in patients with cardiomyopathy and therefore always warrants further investigation with echocardiogram and CMR imaging with perfusion study. Similarly, athletes with severe non-specific interventricular conduction delay (QRS duration $\geq 140 \mathrm{~ms}$ ) should be investigated.

\section{Ventricular pre-excitation}

Ventricular pre-excitation due to an underlying accessory pathway leads to the Wolff-Parkinson-White pattern on the ECG with short PR interval $(<120 \mathrm{~ms}$ ), a delta wave (slurring of initial QRS) and QRS duration $>120 \mathrm{~ms}$, occurs in up to 1 in 250 athletes (Figure 2). ${ }^{38,39}$ An exercise tolerance test should be the first investigation in the athlete, and evidence of abrupt complete loss of accessory pathway with higher heart rates is indicative of a lower risk accessory pathway..$^{40} \mathrm{An}$ echocardiogram is recommended to exclude any associated structural disease such as Ebstein's anomaly or cardiomyopathies. Electrophysiological studies and ablation of the accessory pathway should be considered, particularly in competitive athletes involved in moderate to high-intensity sports, due to risk of a rapidly conducted atrial fibrillation across an accessory pathway, leading to ventricular fibrillation. ${ }^{5}$

\section{Prolonged QT interval}

Prolongation of the QT interval on ECG is the hallmark of congenital long QT syndrome (LQTS), an inherited arrhythmia syndrome with an estimated prevalence of 1 in 2,000 and a predisposition to ventricular arrhythmias and potential SCD. ${ }^{41}$ Prolongation of the QTC $\geq 470 \mathrm{~ms}$ in males and $\geq 480 \mathrm{~ms}$ in females is considered abnormal (Figure 3). Abnormal QT prolongation in the absence of QT-prolonging medications or electrolyte abnormalities warrants further investigation with repeat ECGs and consideration for exercise testing, family screening and potentially genetic testing through a physician with specialised expertise in this area. ${ }^{5,41}$ Features suggestive of LQTS in an 
asymptomatic athlete include relevant family history, QT >500 ms and paradoxical lengthening of the QTC in the fourth minute of recovery of exercise tolerance test. ${ }^{41,42}$

\section{Type 1 Brugada pattern}

Brugada syndrome is an inherited arrhythmia syndrome with a prevalence of 1 in 2,000 characterised by a coved-typed ST elevation in the right praecordial leads (Figure 4). ${ }^{41}$ The coved-type ST elevation in the Brugada ECG pattern is identified by a broad $r^{\prime}$ and a downsloping ST-segment (between the J-point and $80 \mathrm{~ms}$ after the J-point) compared with an upsloping ST-segment in the early repolarisation patterns of an athlete. In an athlete with a borderline Brugada ECG pattern, the ECG should be repeated with high leads (V1-V2 placed in second and third intercostal spaces). The type 1 Brugada ECG pattern in an athlete should always be further investigated for risk of SCD, and first-degree family members should also be reviewed and screened. ${ }^{5,41}$

\section{Multiple premature ventricular contractions or ventricular arrhythmias}

It is considered unusual for an athlete to have $>2$ premature ventricular contractions (PVCS) on baseline ECG and this usually warrants more prolonged ECG monitoring with a Holter monitor to assess the arrhythmic burden. ${ }^{43}$ Athletes generally reveal extrasystoles arising from the right (LBBB with inferior axis) or left (RBBB with inferior axis) ventricular outflow tracts or the left fascicles (relatively narrow RBBB with left or right axis), which resolve with increasing heart rate during exercise; such patterns of PVCs are considered benign. ${ }^{44}$ Other patterns of extrasystoles such as LBBB with superior or intermediate axis or atypical RBBB with QRS $\geq 130$ ms are unusual and may be associated with underlying myocardial disease. The burden of PVCs can be an important marker of underlying structural heart disease. In athletes with $\geq 2,000$ PVCs per 24 hours, up to $30 \%$ have been found to have underlying structural heart disease. ${ }^{33,45}$ In such athletes, or those with increasing ectopy with exercise testing, further investigation is indicated including echocardiogram, CMR imaging and potentially electrophysiological testing including electroanatomic mapping when appropriate or occasionally endomyocardial biopsy. ${ }^{5}$ There is emerging evidence that PVCs conducting with broad RBBB and a superior axis that increase during exercise may represent left ventricular scar. ${ }^{46}$ Identification of subepicardial or midmyocardial scar on CMR imaging, particularly in a striae pattern, is associated with ventricular arrhythmias and SCD in athletes. ${ }^{47}$ Ventricular couplets, triplets and non-sustained ventricular tachycardia always requires further investigation to evaluate for structural heart disease, ARVC or other cardiomyopathies. ${ }^{5}$ If underlying genetic heart disease is suspected, then genetic testing can be useful in some circumstances (Figure 5). ${ }^{48}$

\section{Conclusion}

There are a number of electrical patterns that can develop as part of the athletic adaptation of the heart. However, there are also some ECG abnormalities that should be considered as red flags to the reviewing physician of underlying structural, arrhythmic or inherited heart disease. It is important to ensure ECGs of athletic individuals are reviewed and interpreted by a physician who is trained in differentiating physiology from pathology in this special population. $\square$
1. D'Silva A, Sharma S. Management of young competitive athletes with cardiovascular conditions. Heart. 2017;103:463-73.

2. Corrado D, Basso C, Rizzoli G, et al. Does sports activity enhance the risk of sudden death in adolescents and young adults? I Am Coll Cardiol 2003:42:1959-63.

3. Bagnall $R D$, Weintraub $R G$, Ingles $J$, et al. A prospective study of sudden cardiac death among children and young adults. N Engl I Med. 2016:374:2441-52.

4. Malhotra A, Dhutia H, Finocchiaro G, et al. Outcomes of cardiac screening in adolescent soccer players. N Eng/ I Med. 2018;379:524-34.

5. Sharma S, Drezner JA, Baggish A, et al. International recommendations for electrocardiographic interpretation in athletes. J Am Coll Cardiol. 2017;69:1057-75.

6. Harmon KG, Asif IM, Maleszewski JJ, et al. Incidence and etiology of sudden cardiac arrest and death in high school athletes in the United States. Mayo Clin Proc. 2016;91:1493-502.

7. Harmon KG, Asif IM, Maleszewski JJ, et al. Incidence, cause, and comparative frequency of sudden cardiac death in national collegiate athletic association athletes: a decade in review. colrculation. 2015:132:10-9.

8. Prakash $\mathrm{K}$, Sharma S. The electrocardiogram in highly trained athletes Clin Sports Med 2015:34:419-31.

2. Corrado D, Pelliccia A, Heidbuchel $\mathrm{H}$, et al. Recommendations for interpretation of 12-lead electrocardiogram in the athlete Eur Heart J. 2010;31:243-59.

10. Corrado D, Biffi A, Basso C, et al. 12-lead ECG in the athlete: physiological versus pathological abnormalities. Br I Sports Med. 2009;43:669-76.

11. Marek J, Bufalino V, Davis J, et al. Feasibility and findings of arge-scale electrocardiographic screening in young adults: data from 32,561 subjects. Heart Rhythm. 2011:8:1555-9.

12. Papadakis $M$, Basavarajaiah $S$, Rawlins J, et al. Prevalence and significance of T-wave inversions in predominantly Caucasian significance of T-wave inversions in predominantly Car

13. Papadakis M, Carre F, Kervio G, et al. The prevalence, distribution, and clinical outcomes of electrocardiographic repolarization patterns in male athletes of African/Afro-Caribbean origin. Eur Heart 1. 2011:32:2304-13.

14. Sheikh N, Papadakis M, Carre F, et al. Cardiac adaptation to exercise in adolescent athletes of African ethnicity: an emergent elite athletic population. Br J Sports Med 2013;47:585-92

15. Rawlins J, Carre F, Kervio G, et al. Ethnic differences in physiological cardiac adaptation to intense physical exercise in highly trained female athletes. Circulation. 2010;121:1078-85.

16. Dhutia H, Malhotra A, Finocchiaro G, et al. Impact of the international recommendations for electrocardiographic interpretation on cardiovascular screening in young athletes. J Am Coll Cardiol. 2017:70:805-7.

17. Mont L, Pelliccia A, Sharma S, et al. Pre-participation cardiovascular evaluation for athletic participants to prevent sudden death: position paper from the EHRA and the EACPR branches of the ESC. Endorsed by APHRS, HRS, and SOLAECE. Eur J Prev Cardiol. 2017:24:41-69.

18. Northcote RJ, Canning GP, Ballantyne D. Electrocardiographic findings in male veteran endurance athletes. $B r$ Heart $J$. 1989;61:155-60.

19. Sharma S, Whyte G, Elliott P, et al. Electrocardiographic changes in 1000 highly trained junior elite athletes. Br I Sports Med. 1999:33:319-24.

20. Huston TP, Puffer JC, Rodney WM. The athletic heart syndrome N Engl J Med. 1985;313:24-32.

21. Prakash K, Sharma S. Interpretation of the electrocardiogram in athletes. Can J Cardiol. 2016;32:438-51.

22. Haissaguerre M, Derval N, Sacher F, et al. Sudden cardiac arrest associated with early repolarization. $N$ Eng/ J Med. 2008;358:2016-23

23. Zaidi A, Ghani S, Sheikh N, et al. Clinical significance of electrocardiographic right ventricular hypertrophy in athletes: comparison with arrhythmogenic right ventricular cardiomyopathy and pulmonary hypertension. Eur Heart $\mathrm{J}$. 2013:34:3649-56.

24. Zaidi A, Ghani S, Sharma R, et al. Physiological right ventricular adaptation in elite athletes of African and Afro-Caribbean origin. Circulation. 2013;127:1783-92.

25. D'Ascenzi F, Anselmi F, Piu P, et al. Cardiac magnetic resonance normal reference values of biventricular size and function in male athlete's heart. JACC Cardiovasc Imaging. 2019;12:1755-65.

26. Antzelevitch C, Yan GX, Ackerman MJ, et al. J-wave syndromes expert consensus conference report: Emerging concepts and gaps in knowledge. Heart Rhythm. 2016;13:e295-324.

27. Malhotra A, Dhutia H, Gati S, et al. Anterior T-wave inversion in young white athletes and nonathletes: prevalence and significance. J Am Coll Cardiol. 2017;69:1-9.

28. Brosnan MJ, Te Riele A, Bosman LP, et al. Electrocardiographic features differentiating arrhythmogenic right ventricular cardiomyopathy from an athlete's heart. JACC Clin Electrophysiol. 2018;4:1613-25.

29. Brosnan M, La Gerche A, Kalman 」, et al. Comparison of frequency of significant electrocardiographic abnormalities in endurance versus nonendurance athletes. $\mathrm{Am} \perp \mathrm{Cardiol}$ 2014:113:1567-73.

30. Migliore F, Zorzi A, Michieli P, et al. Prevalence of cardiomyopathy in Italian asymptomatic children with electrocardiographic T-wave inversion at preparticipation screening. Circulation. 2012;125:529-38.

31. Tanriverdi $\mathrm{H}$, Kaftan $\mathrm{HA}$, Evrengul $\mathrm{H}$, et al. QT dispersion and left ventricular hypertrophy in athletes: relationship with angiotensin-converting enzyme I/D polymorphism. Acta Cardiol. 2005;60:387-93.

32. Martin AB, Perry JC, Robinson JL, et al. Calculation of QTC duration and variability in the presence of sinus arrhythmia. Am I Cardiol. 1995;75:950-2.

33. Dhutia H, Malhotra A, Parpia S, et al. The prevalence and significance of a short QT interval in 18,825 low-risk individuals including athletes. Br J Sports Med. 2016;50:124-9.
34. MacAlpin RN. Clinical significance of QS complexes in V1 and $\mathrm{V} 2$ without other electrocardiographic abnormality. Ann Noninvasive Electrocardiol. 2004;9:39-47.

35. Chandra N, Bastiaenen R, Papadakis M, et al. Prevalence of electrocardiographic anomalies in young individuals: relevance to a nationwide cardiac screening program. J Am Coll Cardiol. 2014;63:2028-34.

36. Finocchiaro $\mathrm{G}$, Papadakis $\mathrm{M}$, Dhutia $\mathrm{H}$, et al. Electrocardiographic differentiation between 'benign T-wave inversion' and arrhythmogenic right ventricular cardiomyopathy. Europace. 2019;21:332-8.

37. Schnell F, Riding N, O'Hanlon R, et al. Recognition and significance of pathological T-wave inversions in athletes. Circulation. 2015;131:165-73.

38. Surawicz B, Childers R, Deal BJ, et al. AHA/ACCF/HRS recommendations for the standardization and interpretation of the electrocardiogram: part III: intraventricular conduction disturbances: a scientific statement from the American Heart Association Electrocardiography and Arrhythmias Committee, Council on Clinical Cardiology; the American College of Cardiology Foundation; and the Heart Rhythm Society. Endorsed by the International Society for Computerized Electrocardiology. J Am Coll Cardiol. 2009;53:976-81.

39. Fudge J, Harmon KG, Owens DS, et al. Cardiovascular screening in adolescents and young adults: a prospective study comparing the Pre-participation Physical Evaluation Monograph 4th Edition and ECG. Br I Sports Med. 2014;48:1172-8.

40. Pediatric and Congenital Electrophysiology Society, Heart Rhythm Society, American College of Cardiology Foundation, et al. PACES/HRS expert consensus statement on the management of the asymptomatic young patient with a Wolff-Parkinson-White (WPW, ventricular preexcitation) electrocardiographic pattern . developed in partnership betwen the Pediatric and Congenital Electrophysiology between the Pediatic and Congenital Electrophysiology Society (PACES) and the Heart Rhyth Endorsed by the American College of Cardiology Foundation (ACCF), the American Heart Association (AHA), the American Academy of Pediatrics (AAP), and the Canadian Heart Rhythm Society (CHRS). Heart Rhythm. 2012;9:1006-24

41. Priori SG, Wilde AA, Horie M, et al. HRS/EHRA/APHRS expert consensus statement on the diagnosis and management of patients with inherited primary arrhythmia syndromes: document endorsed by HRS, EHRA, and APHRS in May 2013 and by ACCF, AHA, PACES, and AEPC in June 2013. Heart Rhythm. 2013;10:1932-63.

42. Sy RW, van der Werf C, Chattha IS, et al. Derivation and validation of a simple exercise-based algorithm for prediction of genetic testing in relatives of LQTS probands. Circulation. 2011;124:2187-94.

43. Corrado D, Drezner JA, D'Ascenzi F, Zorzi A. How to evaluate premature ventricular beats in the athlete: critical review 
and proposal of a diagnostic algorithm. Br J Sports Med.

$$
\text { 2020;54:1142-8. }
$$

44. Verdile L, Maron BJ, Pelliccia A, et al. Clinical significance of exercise-induced ventricular tachyarrhythmias in trained exercise-induced ventricular tachyarrhythmias in trained 2015:12:78-85.
45. Biffi A, Pelliccia A, Verdile L, et al. Long-term clinical significance of frequent and complex ventricular tachyarrhythmias in trained athletes. J Am Coll Cardiol. 2002:40:446-52.

46. Zorzi A, De Lazzari M, Mastella $\mathrm{G}$, et al. Ventricular arrhythmias in young competitive athletes: prevalence, determinants, and in young competitive athletes: prevalence, deter
underlying substrate. J Am Heart Assoc. 2018;7.
47. Zorzi A, Perazzolo Marra M, Rigato I, et al. Nonischemic left ventricular scar as a substrate of life-threatening ventricular arrhythmias and sudden cardiac death in competitive athletes Circ Arrhythm Electrophysiol. 2016;9:e004229.

18. Gray B, Semsarian C. Utility of genetic testing in athletes Clin Cardiol. 2020:43:915-20. 